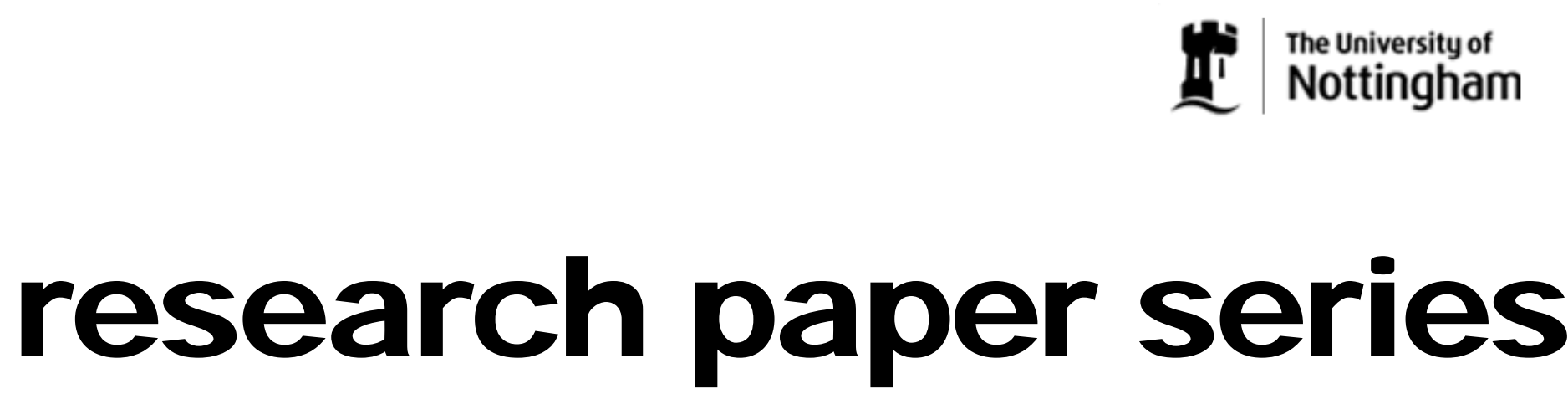

Theory and Methods

Research Paper 2009/16

International Trade and Local Organization of Production

- Two Elementary Propositions

by

Sugata Marjit 


\section{The Authors}

Sugata Marjit is the Reserve Bank of India Professor in the Centre for Studies in Social Sciences, Calcutta, India, and an External Research Fellow in GEP, University of Nottingham.

\section{Acknowledgements}

This paper (with a slightly different title) prepared initially as the A. K. Dasgupta memorial lecture, has benefited from presentations at the Indian Statistical Institute, Kolkata, IGIDR, Mumbai, Midwest Trade Meetings Spring 2009, SUNY at Albany, USA and University of Bamberg, Germany. I would like to thank Ravi Kanbur and Ray Riezman for helpful comments. I am also indebted to Triparna Sinha for able research assistance. The usual disclaimer applies. 


\title{
International Trade and Local Organization of Production - Two Elementary Propositions
}

by

\author{
Sugata Marjit
}

\begin{abstract}
This paper argues that international trade should affect local organization of production in a systematic way. By using the standard Heckscher-Ohlin-Samuelson model we show that the export sector is more likely to demonstrate fragmentation, entrepreneurship and outsourcing compared to the importcompeting sector in a typical labor abundant country. Liberal trade regime will promote entrepreneurship in general. This is the first elementary proposition. Local outsourcing also establishes a clear link between trade and productivity. This is the second elementary proposition.
\end{abstract}

JEL classification: F11, D23, J54, O47

Keywords: Trade, outsourcing, entrepreneurship, productivity

\section{Outline}

1. Introduction

2. Benchmark Model

3. Equilibrium with Fragmentation and Outsourcing in the Export Sector

4. Concluding Remarks 


\section{Non-Technical Summary}

Conventional wisdom underlying the essence of trade theory talks about the country or firm specific local advantages which enable countries and firms to compete successfully in the rest of the world. When trade is allowed to take place, certain products and services flourish and some others decay as they are more cheaply available and possibly in better qualities from other countries. Seldom one explores how trade actually alters the way production is organized within a country. For example how entrepreneurs are groomed through trade, how local services, catering to the needs of the export sectors are developed, how trade enhances local productivity etc. This paper precisely deals with such issues and shows why export sectors are likely to show greater dynamism and local outsourcing in a labour abundant country and how such changes help to improve productivity. It also argues why import competing sectors, in spite of flourishing in a protected regime, would not exhibit such changes. The mechanism has to do with how trade affects cost of capital and volume of production. One interesting point is that the paper uses and extends a well known framework of trade theory and can be easily communicated to the students. 


\section{Introduction}

Fragmentation and outsourcing have been discussed and analyzed extensively in recent literature on trade theory. International fragmentation of production and service related activities and subsequent outsourcing of such fragments are some of the key issues, which have heavily impacted on the policy makers of the developed worlds, primarily in US and Europe. These have implication for intra-country income distribution, employment, migration, research and development, regulation etc. This paper is an attempt to deliberate on a related theme from the perspective of a labour abundant country. A rich trade theoretic literature in the last decade handles all such aspects. Papers by Jones \& Kierzkowski (2003), Deardoff (2001), Jones and Marjit (2001), Marjit (2007), etc discuss the reasons behind fragmentation and its implication for pattern of trade, specialization, income distribution and development process. Recent papers by Grossman and Helpman (2005) and others deal with the issue of outsourcing in terms of heterogeneous firms, incomplete contracts and product variety.

One emerging area of research is this context seems to be the relationship between trade and organization of production. The important question in this context is whether trade alters internal production organization in a firm or in an industry. Helpman (2006) and Antras (2005b) discuss some of these issues in terms of models with heterogeneous firms, trading costs and incompleteness of contracts based on an earlier analysis of Melitz (2003). However, so far traditional trade theoretic framework has not been exploited properly to address the issue of trade, entrepreneurship and local outsourcing. In this paper we use a standard HOS framework to argue why trade will be beneficial for entrepreneurship and local outsourcing in a typical labor abundant economy. We also demonstrate that export sectors are natural candidates for such experimentation. Capital intensive set up and fixed costs for new and small business deter entrepreneurship in general even if some workers can be quite productive as entrepreneurs. Declining capital cost and increase in production of the exportable make fragmentation and entrepreneurship relatively attractive in the export sector. For the import competing sector the favorable cost effect and the scale effect will move against each other. In some recent surveys conducted through fieldwork in India [Maiti and 
Marjit (2007] it has been observed that international trade leads to separation of production and marketing activities. Merchants provide export orders to small fragmented units of production. These merchants are mostly producers of bigger firms which were primarily engaged in production when the markets were mainly local and national. Such separation and specialization of activities have been modeled in a partial equilibrium framework in Maiti and Marjit (2008). This paper is a general equilibrium construct and adopts a completely different mechanism by focusing directly on cost of capital and scale of production.

Jones and Marjit (2001) raised the issue of role of fragmentation in development process by noting the fact that more liberal and open regimes are resisted by "older" generations because they control the source of capital and education. Vertically integrated processes require lumpy capital and "younger" generations can thrive better in world, which allows fragmentation and trade in fragments lowering the requirement of capital. We draw upon this idea but instead of comparing older and younger generations we take a direct route by which more trade reduces cost of capital in a labor abundant economy.

This paper is also related to Jones and Marjit (2008), which provide cases where trade may lead to greater number of activities relative to autarky even if one observes specialization. In this paper greater orientation towards export business will lead to diversified fresh activities hitherto contained in the vertically integrated production process of the export industry. Typically such an outcome will reflect productivity growth of some kind and a regime switch affecting the relationship between commodity prices and factor returns. The relationship between my idea and the one popularly discussed in the literature is that I focus on heterogeneity of occupations of workers who can either toil as workers within in the industry or can set up their own firms. In a way trade creates an environment where entrepreneurial talent flourishes. It flourishes because the scale effect is reinforced by capital cost cutting effect as export sector expands in a labor-abundant country. Even if one abstracts from heterogeneity of firms, moral hazard or adverse selection type problems consistent with contractual complexities, the standard workhouse of trade theory is capable enough to address this issue. Section 2 develops the model and determines equilibrium. Section 3 looks at the effect of trade on fragmentation and outsourcing and analyses the 'productivity' impact and the last one concludes. 


\section{Benchmark Model}

It is a standard $2 \times 2$ HOS framework with $\mathrm{X}$ being the output of the export good and $\mathrm{Y}$ that of the import-competing good. Each sector uses a different intermediate good, which uses only labor and used in fixed proportions with labor and capital.

The competitive price-equations are given by,

$$
\begin{aligned}
& w a_{l x}+r a_{k x}+P_{m_{1}}=P_{x} \\
& \mathrm{wa}_{\mathrm{ly}}+r a_{k y}+P_{m_{2}}=P_{y}(1+\mathrm{t}) \\
& \mathrm{P}_{\mathrm{m}_{1}}=a_{m x} w \\
& \mathrm{P}_{\mathrm{m}_{2}}=a_{m y} w \\
& \mathrm{X}=\mathrm{M}_{1} \\
& \mathrm{Y}=\mathrm{M}_{2}
\end{aligned}
$$

We assume one unit of intermediate is required to produce one unit of final good. While $\mathrm{K}$ and $\mathrm{L}$ are substitutes in the usual neo-classical sense, $\mathrm{M}_{1}$ and $\mathrm{M}_{2}$ are not substitutes and required in fixed proportions. Intermediates $\mathrm{M}_{1}$ and $\mathrm{M}_{2}$ are used in the vertically integrated process with some labor devoted to the production of those within the firm. $t$ is the tariff rate. The full employment conditions are given by

$$
\begin{aligned}
& a_{l_{x}} X+a_{l y} Y+a_{m x} X+a_{m y} Y=L \\
& a_{k x} X+a_{k y} Y=K
\end{aligned}
$$

$(\mathrm{L}, \mathrm{K})$ are given endowments of labor and capital. We have a small open economy, where production technology follows CRS and diminishing marginal productivity. It exports good $\mathrm{X}$ and imports good $\mathrm{Y}, \mathrm{X}$ is labor intensive and $\mathrm{Y}$ is capital intensive. Since we shall work with a fixed set of prices, lets set $P_{X}=P_{y}=1$. Therefore given ( $\left.t, K, L\right)$ we can find out $w$, $\mathrm{r}, \mathrm{X}$ and $\mathrm{Y}$. These in turn determine $\mathrm{P}_{\mathrm{m}_{1}}, \mathrm{P}_{\mathrm{m}_{2}}, \mathrm{M}_{1}$ and $\mathrm{M}_{2}$.

Some of the workers who produce $\mathrm{M}_{1}$ and $\mathrm{M}_{2}$ also have entrepreneurial qualities. If they produce it on their own, they can produce with a better technology, such that $\mathrm{b}_{\mathrm{mx}}<\mathrm{a}_{\mathrm{mx}}$ and $\mathrm{b}_{\mathrm{my}}<\mathrm{a}_{\mathrm{my}}$. We assume that $\mathrm{n}$ such workers can get together, incur a fixed cost of $\mathrm{k}$ and thus the total cost of obtaining such inputs from outside are $\mathrm{wb}_{\mathrm{mx}} \mathrm{X}+\mathrm{rk}$ and 
$\mathrm{wb}_{\mathrm{my}} \mathrm{Y}+\mathrm{rk}$, respectively. Therefore firms producing $\mathrm{X}$ and $\mathrm{Y}$ will like a vertically integrated process iff the following holds:

$$
\begin{aligned}
& w a_{m x} \leq w b_{m x}+\frac{r k}{X} \\
& w a_{m y} \leq w b_{m y}+\frac{r k}{Y}
\end{aligned}
$$

Market structure in the intermediate industry follows "contestability". Positive profits are competed away by free entry and exit assumption. Thus $\mathrm{P}_{\mathrm{m}_{1}}, \mathrm{P}_{\mathrm{m}_{2}}$ to be charged by the outside entrepreneurs are given by the RHS in (9) and (10). Thus n worker-entrepreneurs get together and build up such a firm. Another assumption is that $n>\max \left(b_{m x} X, b_{m y} Y\right)$. This implies that a part of the labor effort goes towards pure entrepreneurial supervision. Rewriting (9) and (10) we get,

$$
\begin{aligned}
& \frac{w}{r}\left(a_{m x}-b_{m x}\right) \leq \frac{k}{X} \\
& \frac{\mathrm{w}}{\mathrm{r}}\left(a_{m y}-b_{m y}\right) \leq \frac{k}{Y}
\end{aligned}
$$

Note that $\frac{\mathrm{w}}{\mathrm{r}}, \mathrm{X}$ and $\mathrm{Y}$ all are impacted by $\mathrm{t}$.

For notational simplicity let us denote $\left(a_{m x}-b_{m x}\right)$ as $d_{x}$ and $\left(a_{m y}-b_{m y}\right)$ as $d_{y}$.

$$
\begin{aligned}
& \frac{\mathrm{w}}{\mathrm{r}}(\mathrm{t}) \leq \frac{\mathrm{k}}{\mathrm{d}_{\mathrm{x}} \cdot \mathrm{X}(\mathrm{t})} \\
& \frac{\mathrm{w}}{\mathrm{r}}(\mathrm{t}) \leq \frac{\mathrm{k}}{\mathrm{d}_{\mathrm{y}} \cdot \mathrm{Y}(\mathrm{t})}
\end{aligned}
$$

If we look at the incentive constraints (13) and (14) more closely, one can easily check that liberal trade policies are likely to generate local outsourcing in "both" sectors. While they unambiguously do it for the export sector, it is likely that they would do it for the importcompeting sector as well.

Rewriting (13) and (14) as (13)' , (14)'

$$
w(t) \geq \frac{r}{X}(t) \cdot d x
$$


$w(t) \geq \frac{r}{X}(t) \cdot d y$

(13)' and (14)' have to hold for outsourcing to be a viable propositions. We now use the standard Stolper-Samuelson and price-output response in HOS framework to draw the figures 1-5.

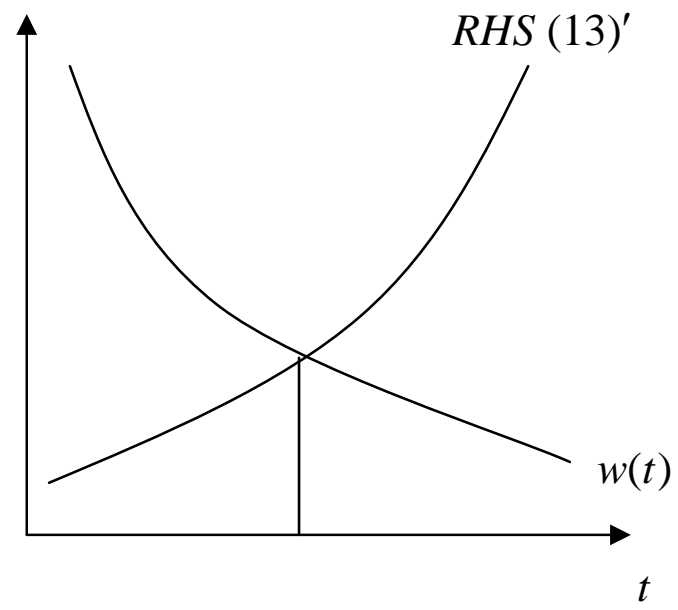

Figure - 1

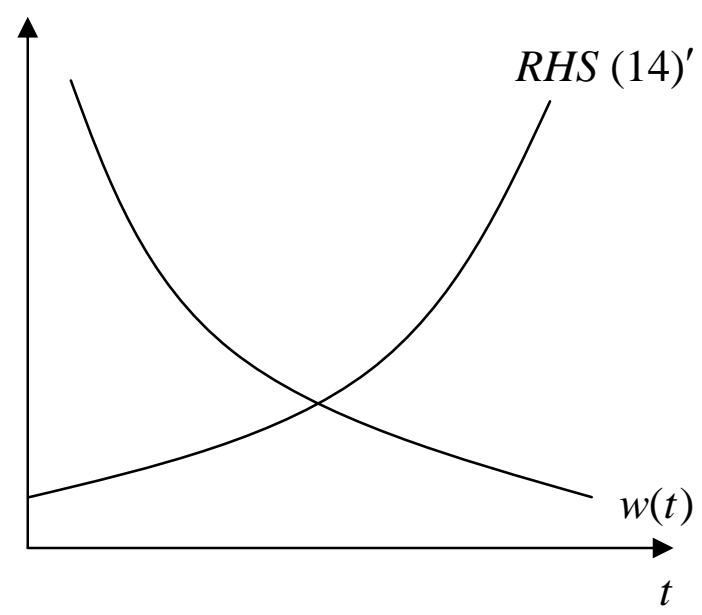

Figure - 2 


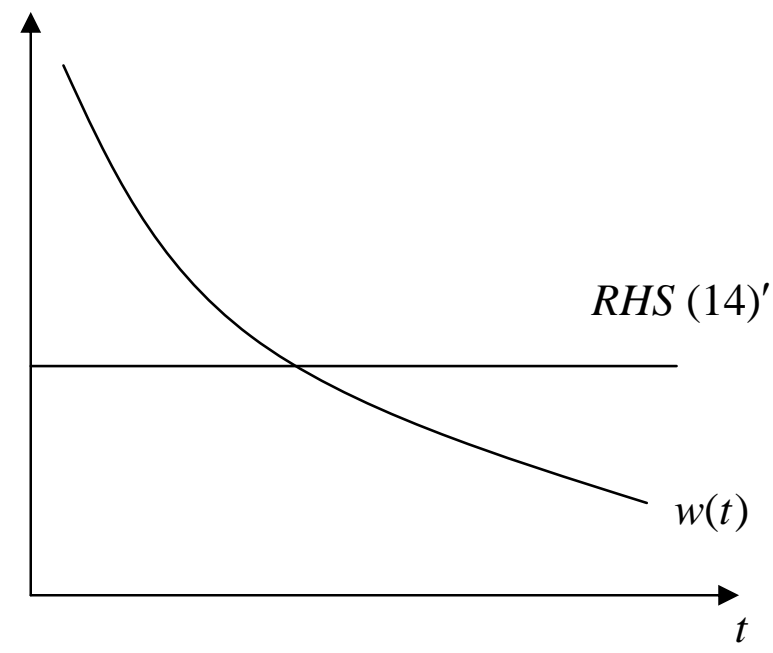

Figure - 3

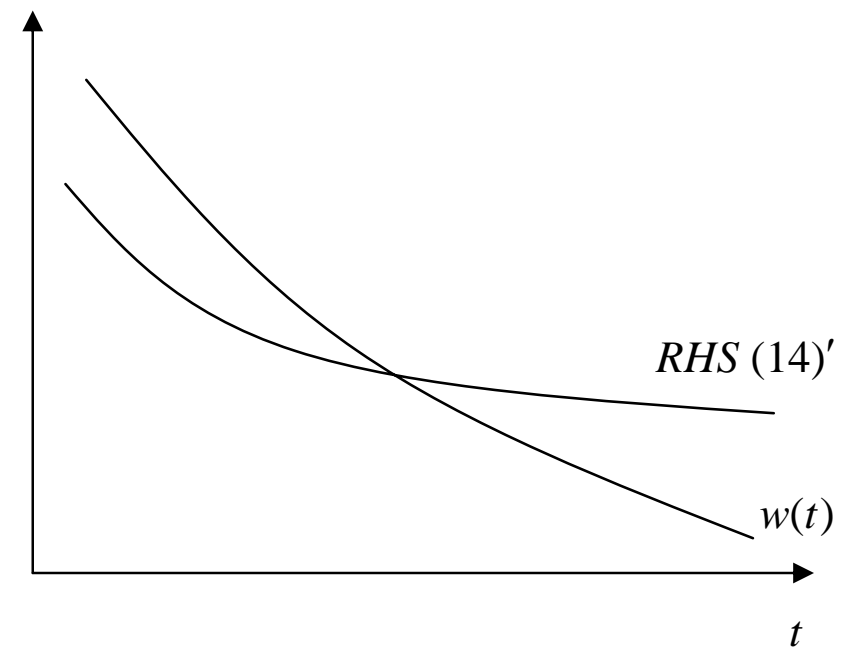

Figure -4

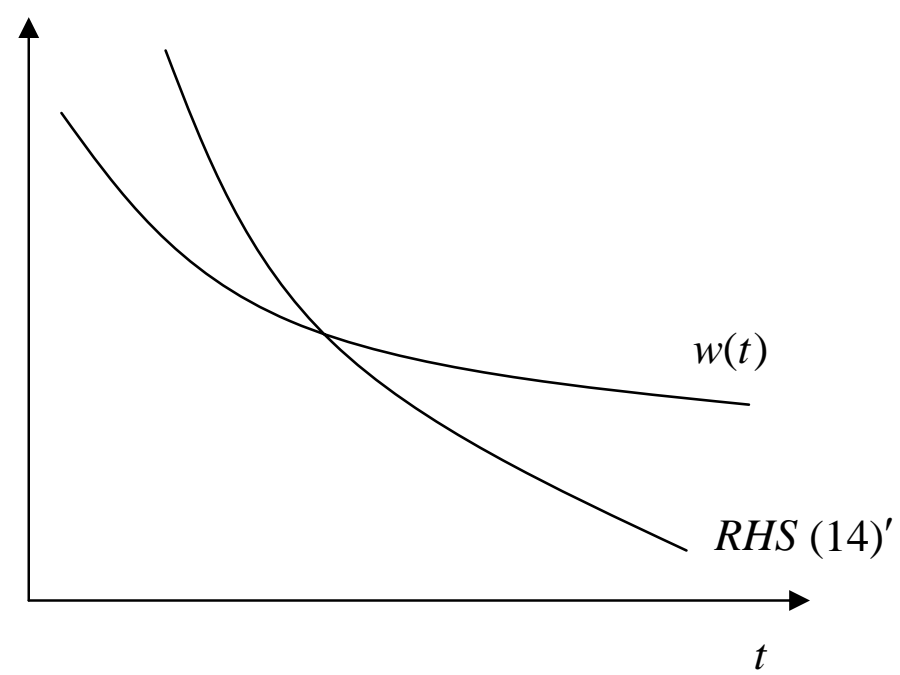

Figure - 5 
Figure - 3 shows that for low enough tariffs export sector will always go for outsourcing. This is the same as figure -1 . Note that as $t$ increases $r$ and $\mathrm{Y}$ both increase. Out of four possible cases if $\frac{r}{Y}$ does not decline too fast, outsourcing will be opted by the importcompeting producers where tariffs are relatively low. Thus for lower tariff both sectors will go for local outsourcing. We are now ready to propose the following:

\section{Proposition I: A low enough tariff will lead to generate fragmentation and local outsourcing in the in the export sector. If a decline in tariff does not sharply reduce $Y$ relative to $r$, lower tariff will also encourage fragmentation and outsourcing in the import-competing sector.}

Proof: See the discussion above.

As tariff goes down cost of capital falls in a labor-abundant country and the exportvolume increases. Both are conducive for entrepreneurship to flourish. Workers in spite of being more productive as entrepreneurs $(\mathrm{dx}>0)$ cannot open their own business because capital is costly. Thus greater trade leads to outsourcing in the export sector.

For the import-competing sector same thing may not happen when $\mathrm{t}$ goes up as cost of capital and volume of $\mathrm{Y}$ both rise at the same time reflecting nothing on the net incentive for outsourcing in the sector. However as we have shown as long as $\frac{r}{Y}(t)$ does not fall too rapidly, the possibility of outsourcing in this sector seems to be greater with a liberal trade policies. Thus local outsourcing is encouraged by lower tariff in this sector as well.

Once tariff clears a critical level fragmentation and local outsourcing become possible and there is a regime shift in the way production is locally organized. Therefore, one needs to solve for the new equilibrium values. We assume that such a switch occurs only in the export sector and specify the equilibrium conditions accordingly. We discuss existence of such equilibrium in detail in the appendix. 


\section{Equilibrium with Fragmentation and Outsourcing in the Export Sector}

The new general equilibrium configuration is as follows:

$$
\begin{aligned}
& w a_{l x}+r a_{k x}+w b_{m x}+\frac{r k}{X(t)}=1 \\
& w a_{l y}+r a_{k y}+w a_{m y}=1+t \\
& \mathrm{a}_{1 x} X+a_{l y} Y+n=\bar{L} \\
& a_{k x} X+a_{k y} Y+k=\bar{K} \\
& X=M_{1} \\
& \mathrm{Y}=\mathrm{M}_{2}
\end{aligned}
$$

$\mathrm{n}$ workers gather together and use $\mathrm{k}$ as the business set-up cost and supply the intermediate input from outside. $\mathrm{n}>\mathrm{b}_{\mathrm{mx}} \mathrm{X}$ Because a part of labor goes towards pure entrepreneurial activities beyond production related work. Given (t, w, $k, \bar{L}, \bar{K}$ ) we determine w, r, X, Y, $\mathrm{M}_{1}$ and $\mathrm{M}_{2}$ from (15) - (20).

For each $\mathrm{X}(\mathrm{t})$ we can derive another through this process by a function defined as $\phi(\mathrm{X}(\mathrm{t}))$. The solution process implies whether there is a fixed point of the form $X(t)=\varphi(X(t))$

As $\mathrm{X}(\mathrm{t})$ increases $\frac{\mathrm{w}}{\mathrm{r}}$ must increase as $\mathrm{X}$ is labor-intensive. This is through productivity effect in (15). This should imply an increase in X(t) from (17) and (18). These are all standard HOS outcomes. Thus $\phi^{\prime}(\mathrm{X}(\mathrm{t}))>0$. Existence and uniqueness of $\mathrm{X}(\mathrm{t})$ are assumed. We are more interested in the consequence of such an outcome on $\mathrm{X}(\mathrm{t})$ and factor returns. The formal proofs will be worked out later. (See the Appendix) 


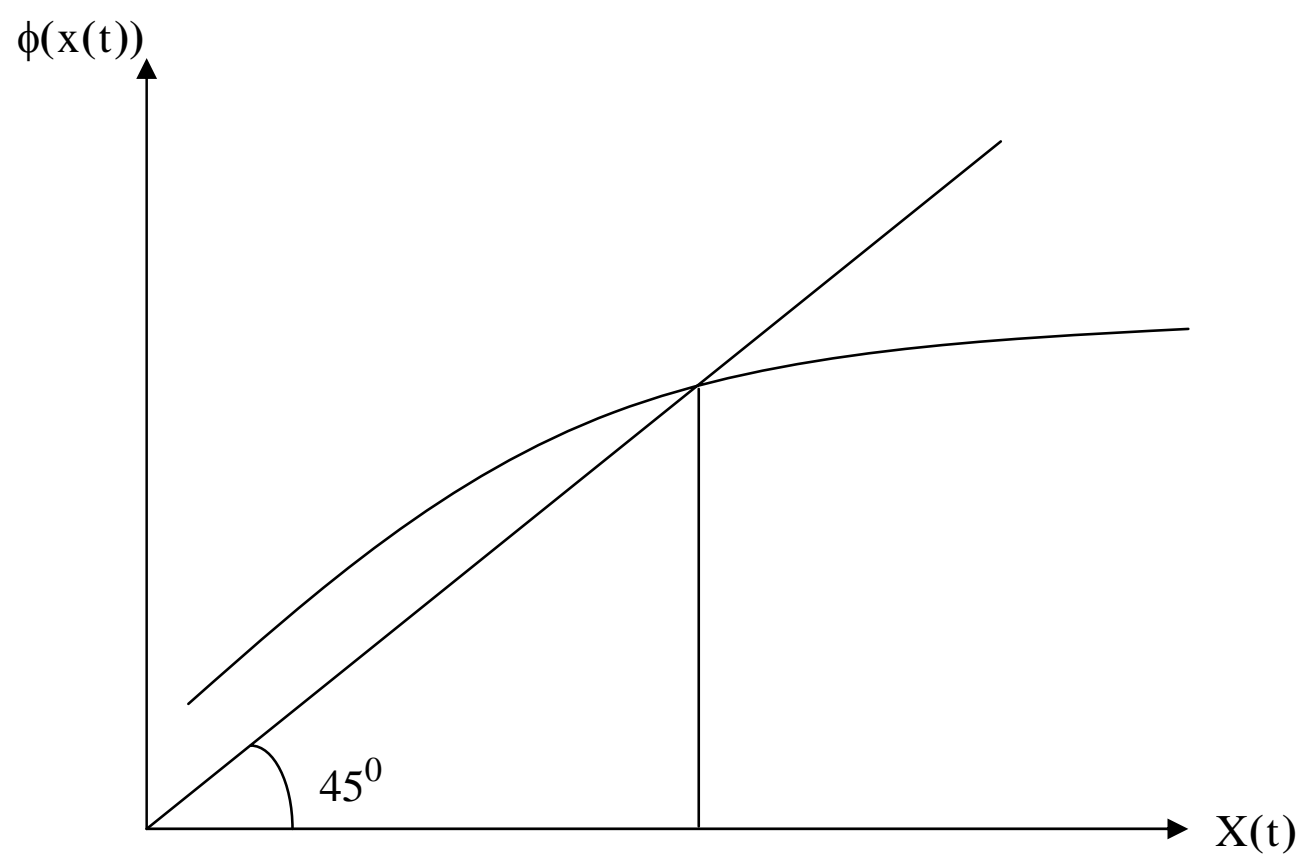

Figure -6

Note that as long as the tariff is not reduced substantially such fragmentation and outsourcing will not take place. However, once tariff reaches the critical threshold the process will be activated. Two points we need to highlight here.

First, there will be a 'finite' change in the process reflecting a jump as workers shift themselves from inside to outside factory. Second, this will have a positive productivity impact for the $\mathrm{X}$ sector. Thus trade will have a distinct productivity impact. Such a growth in productivity will affect factor returns immediately. As figure-3 suggests as soon as $t$ is lowered beyond a critical level, $\frac{\mathrm{W}}{\mathrm{r}}$ jumps up and then again follows a monotonically increasing trajectory. 


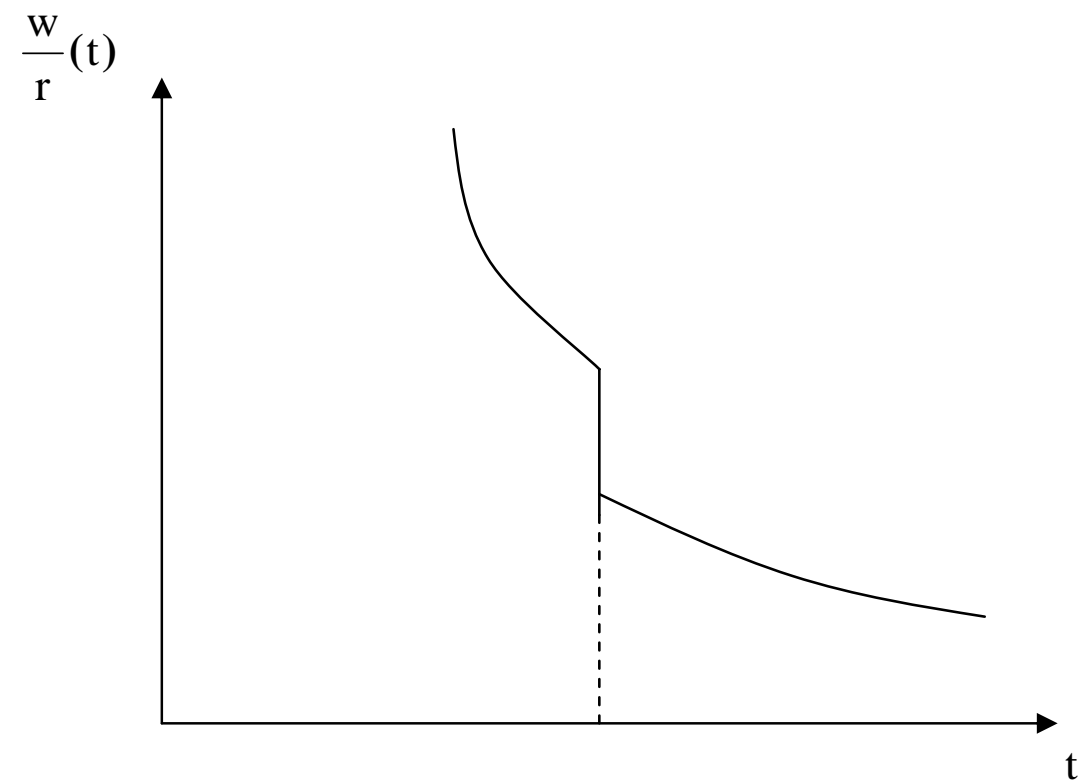

Figure -7

It is also expected that $\frac{\mathrm{W}}{\mathrm{r}}$ will increase at a sharper rate beyond the critical point as laborintensities decline and capital-intensities increase for sector X. Thus the Stolper-Samuelson type outcome gets a further boost.

Once the average cost of obtaining the intermediate input is directly related to the tariff rate, a decline in tariff also means a decline in effective cost of production for the export good. This is just like a productivity effect which will increase the wage rate.

Proposition II : Liberal trade regime will reduce the cost of locally outsourced input and enhance productivity of labor-abundant country.

Proof: See the discussion above.

One issue that needs to be addressed is the transition from the state of nooutsourcing to outsourcing. As we have demonstrated the post-outsourcing equilibrium will 
throw up some $\mathrm{w}$ and $\mathrm{r}$, call them $\mathrm{w}_{2}$ and $\mathrm{r}_{2}$. We also know that for outsourcing to be profitable we must have

$$
\mathrm{w}_{1} \mathrm{a}_{\mathrm{mx}} \geq \mathrm{w}_{2} \mathrm{~b}_{\mathrm{mx}}+\frac{\mathrm{r}_{2} \mathrm{k}}{\mathrm{X}(\mathrm{t})}
$$

Suppose $\left(\mathrm{w}_{2}, \mathrm{r}_{2}, \mathrm{X}(\mathrm{t})\right)$ are such that strict equality holds for (22). Then there should not be any productivity effect of outsourcing. In the new equilibrium w and $\mathrm{r}$ will remain the same. With strict inequality $\mathrm{w}$ will increase and $\mathrm{r}$ will fall and the workers have incentive to set up their own business. An element of bargaining may be latent here if entrepreneurs form a syndicate and bargain for the reservation price of the intermediate in case there is no outsourcing. In our structure $n>b_{m x} X$ implying part of the labor effort goes towards specific entrepreneurial activities. The extent of such labor is given by $\left(\mathrm{n}-\mathrm{b}_{\mathrm{mx}} \mathrm{X}\right)$, net of labor used for production. A decline in $\mathrm{n}$ will reflect improvement in entrepreneurial talent. This has usual general equilibrium implications. A fall in $\mathrm{n}$ will, via Rybczynski effect, increase output of $\mathrm{X}$ and reduce that of $\mathrm{Y}$. Again this will have productivity effect acting through $\frac{\mathrm{rk}}{\mathrm{X}(\mathrm{t})}$ and raising w and reducing r via Stolper-Samuelson outcome.

Two issues need to be highlighted here:

First, in case the intermediate input is a traded input, fragmentation and outsourcing do not provide any extra benefit to the sector producing $X$ except that some productive entrepreneur-workers locate themselves out of the industry. Further decline in t will increase wage via Stolper-Sameulson effect, but will not confer any additional productivity benefit. The fact that the price of the intermediate can fall, provides the extra productivity boost.

Second, we have assumed that in the post-outsourcing the input is available at the average cost. But that may not be the case. The equilibrium price may be a contracted price. But such a price must be a positive function of the average cost and to that extent a rise in $\mathrm{X}$ will reduce the price of the intermediate input. 


\section{Concluding Remarks}

Contemporary research in theory of international trade puts a lot of emphasis on the interaction between international trade and organization of production such as fragmentation and outsourcing. While heterogeneity of firms within an industry opens up huge reservoir of possibilities where different firms choose different modes of operations, even within the ambit of the Hecksher-Ohlin-Samuelson type set up the export sector can be a natural domain for outsourcing related activities. We focus on indigenous outsourcing and entrepreneurship and formalize the crucial link between trade and productivity.

If $\mathrm{P}_{\mathrm{m}}$ is the initial price, the export firms were willing to pay and the entrepreneurs can provide the service at a lower cost, who will grab the difference? In our framework such difference helps all workers through a rise in w. But ideally it must generate a special class of worker-entrepreneurs. In this context sector-specific skill is a better way to capture the essence of the problem. Thus imperfect competition, heterogeneity of workforce, sectorspecific skills all are possible domains of further works. Also simultaneous outsourcing in export and import competing sector will be a welcome exercise. Contractual complexities are also important. To outsource activities one needs to think of monitoring and provision of optimal contracts depending on the informational problem. Such work is becoming popular in trade theory, but not in terms of the standard text book model of trade. Such issues are discussed at length in Helpman (2006) in models of product differentiation and heterogeneity of firms. But similar scopes are available in the more conventional models of trade theory. This is the key point of the paper. 


\section{Reference}

Antràs, P. 2003 "Firms, Contracts, and Trade Structure". Quarterly Journal of Economics, 118 (4): 1375-1418.

Antras, P. and Helpman E., 2004. "Global Sourcing," Journal of Political Economy, 112(3): 552-580.

Deardorff, A. V., 2001. "Fragmentation in simple trade models," The North American Journal of Economics and Finance, 12(2): 121-137.

Grossman, G. M. and Helpman, E. 2005: "Outsourcing in a Global Economy" Review of Economic Studies, 72: 135-159.

Helpman, E. 2006. "Trade, FDI, and the Organization of Firms," Journal of Economic Literature, 44(3): 589-630.

Jones, R.W. and Kierzkowski, H. (2005), 'International Fragmentation and the New Economic Geography', The North American Journal of Economics and Finance 16(1): 1-10.

Jones, R.W. and Marjit S. 2001 'The role of International fragmentation in the Development Process ‘- American Economic Review, 91(2): 363-366.

Jones, R. W. and S. Marjit (2008), “Competitive Trade Models with Real World Features”, Economic Theory. ( Published Online, Sep 2008)

Marjit, S. 2007. “ Trade Theory and the Role of Time Zones” International Review of Economics and Finance, 16(2): 153-160.

Melitz, M. J. 2008. "International Trade and Heterogeneous Firms", New Palgrave Dictionary of Economics, 2nd Edition.

Melitz, M. J. 2003 The Impact of Trade on Intra-Industry Reallocations and Aggregate Industry Productivity," Econometrica, 71(6): 1695-1725. 


\section{Appendix}

\section{Existence of an Outsourcing Equilibrium in the export sector}

Let the initial no-outsourcing situation generates $\left(\mathrm{w}_{0}, \mathrm{r}_{0}, \mathrm{X}_{\mathrm{o}}, \mathrm{Y}_{\mathrm{o}}\right)$ as equilibrium outcomes. The new equilibrium with outsourcing is represented by ( $\mathrm{w}, \mathrm{r}, \mathrm{X}, \mathrm{Y}$ ).

Equation (15) - (21) determine the equilibrium and (22) must hold (with $\mathrm{w}_{1}$ replaced by $\mathrm{w}_{0}$ and $\mathrm{w}_{2}$ replaced by $\mathrm{w}$ and $\mathrm{r}_{2}$ by $\mathrm{r}$ ). Let us define

$\mathrm{wb}_{\mathrm{mx}}+\frac{\mathrm{rk}}{\mathrm{x}}=\mathrm{P}_{\mathrm{mx}}$

Outsourcing, as argued in the paper, is caused by a decline in $\mathrm{t}$, with $\mathrm{n}$ and $\mathrm{k}$ jumping from an initial value of zero to some positive number. The new equilibrium must be such that (22) holds with strict inequality.

The proof of existence proceeds as follows.

Step I. Find the effect of $\mathrm{n}>0, \mathrm{k}>0$ and a declining t on $\mathrm{X}$ and the condition that $\hat{\mathrm{x}}>0 .\left[\hat{\mathrm{x}} \equiv \frac{\mathrm{dx}}{\mathrm{x}}\right]$

Step II. Find out the effect on $\mathrm{P}_{\mathrm{mx}}$ and the condition that $\hat{\mathrm{P}}_{\mathrm{mx}}<0$.

Working with (15) - (21) and using Jones (1965) it is easy to check that

$$
\hat{\mathrm{X}}=\frac{(\hat{\mathrm{w}}-\hat{\mathrm{r}}) \delta_{\mathrm{x}}}{|\lambda|}-\frac{\lambda_{\mathrm{L} 3} \lambda_{\mathrm{Ky}}}{|\lambda|} \cdot \hat{n}+\frac{\lambda_{\mathrm{K} 3} \lambda_{\mathrm{Ly}}}{|\lambda|}
$$

where $\delta_{\mathrm{x}}=\left(\lambda_{\mathrm{Lx}} \alpha \sigma_{\mathrm{x}} \theta_{\mathrm{Kx}}+\lambda_{\mathrm{Ly}} \sigma_{\mathrm{y}} \theta_{\mathrm{Ky}}\right)$ and $\lambda_{\mathrm{s}}, \sigma_{\mathrm{s}}, \theta_{\mathrm{s}}$ have usual interpretation. $\sigma_{\mathrm{x}}$ is adjusted by $\alpha$ to reflect the fact that $\mathrm{M}$ is used in fixed proportions with labor and capital in X. $\lambda_{\mathrm{L} 3}$ is share of $\mathrm{n}$ in total $\mathrm{L}$ and $\lambda_{\mathrm{K} 3}$ is share of $\mathrm{k}$ in total $\mathrm{K}$.

Solving for $(\hat{\mathrm{W}}-\hat{\mathrm{r}})$ from (15) and (16) we get

$\hat{\mathrm{X}}=\frac{\delta_{\mathrm{X}} \theta_{\mathrm{K}} \hat{\mathrm{X}}}{|\theta| \lambda \mid}-\frac{\hat{\mathrm{T}}}{|\theta||\lambda|}-\hat{\mathrm{n}} \cdot \frac{\lambda_{\mathrm{L} 3} \lambda_{\mathrm{Ky}}}{|\lambda|}+\hat{\mathrm{k}} \frac{\lambda_{\mathrm{K} 3} \lambda_{\mathrm{Ly}}}{|\lambda|}$ 
where $\hat{T}=(1+t)$

Note that $|\theta>0|,|\lambda|>0$ as $\mathrm{X}$ is labor intensive. (2A) captures the following.

(a) The first term is nothing but formal representatives of (21). For stability $1-\frac{\delta_{\mathrm{X}} \theta_{\mathrm{K}}}{|\theta| \lambda||}<1$. The fixed point is derived on the transformed space $\hat{\mathrm{X}}$ rather than on $\mathrm{X} . \theta_{\mathrm{K}}$ is share of capital in the unit cost of the intermediate.

(b) $\hat{\mathrm{T}}<0$ implies $(\hat{\mathrm{W}}-\hat{\mathrm{r}})>0$, as well as $\hat{\mathrm{X}}>0$.

(c) $\hat{\mathrm{n}}>0$ and $\hat{\mathrm{k}}>0$ have opposite effects on $\hat{\mathrm{X}}$.

(d) If $\lambda_{\mathrm{L} 3}$ and $\lambda_{\mathrm{K} 3}$ are negligible i.e. $\mathrm{n}$ and $\mathrm{k}$ are small relative to total $\mathrm{K}$ and $\mathrm{L}$, we have

$$
\hat{\mathrm{X}}=-\frac{\hat{\mathrm{T}}}{|\theta \| \lambda|}\left[\frac{1}{1-\frac{\delta_{\mathrm{X}} \theta_{\mathrm{K}}}{|\theta| \lambda||}}\right]
$$

As $t$ goes down, even if workers leave the export sector to become entrepreneurs and capital is released from production for setting up the business, $\mathrm{X}$ will rise in equilibrium. From (3A) we can stipulate that following is a set of sufficient conditions under which $\hat{\mathrm{X}}>0$.

(i) $\lambda_{\mathrm{L} 3} \cong 0, \quad \lambda_{\mathrm{K} 3} \cong 0$

(ii) $1>\delta_{\mathrm{x}} \cdot \frac{\theta_{\mathrm{k}}}{|\theta| \lambda||}$

Along with (i) and (ii) we must have (iii)

(iii) $\operatorname{Lim}_{\mathrm{t} \rightarrow 0}\left[\mathrm{w}(\mathrm{t}) \mathrm{b}_{\mathrm{mx}}+\frac{\mathrm{r}}{\mathrm{X}}(\mathrm{t}) \mathrm{k}_{\mathrm{x}}\right]<\operatorname{Lim}_{\mathrm{t} \rightarrow 0} \mathrm{w}(\mathrm{t}) \mathrm{a}_{\mathrm{mx}}$

(iv) guarantees that $\exists \mathrm{t} \quad$ s.t $\quad \mathrm{w}(\mathrm{t})>\frac{\mathrm{r}}{\mathrm{X}}(\mathrm{t}) \cdot \frac{\mathrm{k}}{\mathrm{dx}}$. 